\title{
Odontology prize 2021
}

(c) The Society of The Nippon Dental University 2021

Amal Alharbi, Stefano Ardu, Tissiana Bortolotto and Ivo Krejci were awarded the ODONTOLOGY PRIZE 2021 for the best science paper in recognition of outstanding originality and significance in the paper.

"Stain susceptibility of composite and ceramic CAD/ CAM blocks versus direct resin composites with different resinous matrices".
Odontology, volume 105, number 2, page 162-169, 2017.

Publisher's Note Springer Nature remains neutral with regard to jurisdictional claims in published maps and institutional affiliations. 